\title{
Regional oxidative stress in encephalon of female mice with polyphenolic exposure from tea extracts in oral overweight plant-based treatment
}

\author{
Agustín Ramiro MIRANDA, MD ${ }^{1,2}$; María Cecilia CITTADINI, BSc ${ }^{1,2}$; Claudia ALBRECHT, PhD ${ }^{1,2}$; \\ Elio Andrés SORIA, MD PhD'.
}

1 Instituto de Investigaciones en Ciencias de la Salud, Universidad Nacional de Córdoba, CONICET, FCM (Enrique Barros, Ciudad Universitaria, CP 5014 Telephone/Fax: +543514334020), Córdoba, Argentina. Corresponding author: easoria@fcm.unc.edu.ar

2 Instituto Nacional del Cáncer, Ministerio de Salud de la Nación (Av. Julio A. Roca 781 10², CABA), Buenos Aires, Argentina.

\begin{abstract}
Polyphenols provide by diet may act as antioxidant in the Central Nervous System and exert a protective effect on metabolic diseases. The aim of this study was to establish tea extract effects on oxidative status and murine overweight in accordance with polyphenolic availability in different encephalic regions. Methods: Balb/c mice (female, $\mathrm{n}>3$ ) with overweight received for 15 days $100 \mathrm{mg} / \mathrm{Kg} / \mathrm{d}$ of extract from Lantana grisebachii, Aspidosperma quebrachoblanco, or Ilex paraguariensis extracts and control group (received water without extract). Body weight gain was recorded regularly. Polyphenols, hydroperoxides (HP), lipid peroxides (LP), and superoxide anion (SO) were measured in brain (telencephalon and diencephalon), midbrain, brainstem and cerebellum. Results were compared by ANOVA followed by the Tukey test $(P<0.05)$. Results: $A$. quebracho-blanco-based treatment decreased weight gain and increased polyphenols in brainstem $(p<0.02)$, although it concomitantly increased SO and LP in this region $(p=0.0029$ and $p=0.0280$, respectively). L. grisebachii-based treatment reduced oxidative markers differentially in each region $(p<0.05)$. I. paraguariensis-based treatment oxidized midbrain and cerebellum, although it was antioxidant in the brainstem $(p<0.05)$. All treatments were antioxidant in telencephalon $(p=0.0029)$. Conclusions: The $A$. quebrachoblanco extract was active on overweight and increased polyphenols in brainstem, with safe functional derivatives being required to avoid oxidative stress. Other extracts affected oxidative status in a region-dependent manner.
\end{abstract}

Keywords: central nervous system; aspidosperma quebracho-blanco; ilex paraguariensis; lantana grisebachii; obesity; infusion. Graphical abstract

\begin{tabular}{|l|l|l|}
\hline Aspidasperma quebracho-blanco extract \\
Brainstem: \\
1 Polyphenols bioavialibity \\
i Oxidants concentration \\
Telencephalon: \\
1 Oxidants concentration
\end{tabular}

\section{Introduction}

Plant polyphenols are xenohormetic compounds with health potential ${ }^{1}$, which are provided by ve- getable foods (e.g. fruits, vegetables, cereals, oli- ves, vegetables, cocoa, coffee etc.) and drinks, such as teas or infusions . Then, they cross blood-brain barrier and enter in the central ner- vous system ${ }^{3}$, to exert several redox and different regulative effects ${ }^{4}$. Given this, they prevent the development of chronic non-communicable di- seases, such as overweight and obesity, involving redox-related chronicity. Thus, bioprospecting in American flora can provide some bioactive antioxidant polyphenols to be included as nutritional or pharmacological agents for the control of the- se health problems, which elevated morbidity and mortality worldwide . 
Organic regulation of body weight depends on the participation of different brain regions (cere- bral cortex, hypothalamus and brainstem), and other interrelated systems and their mediators (e.g. digestive and endocrine ones) $^{7}$. In this sen- se, polyphenols extracted by plant infusion are available natural compounds, which can modulate functions of these systems ${ }^{8}$. Furthermore, their tissue concentrations in telencephalon and diencephalon are inversely correlated to body weight gain (unpublished results). Nonetheless, polyphenols need to be analyzed by a pharmaco- nutritional approach to assess their sources, bioa- vailability, desirable and undesirable effects , in order to discern between their positive and toxic activities.

Previous reports support selection of the following plants to assay their extracts ${ }^{11,12}$ : Lantana grise- bachii Stuck. (Verbenaceae) (LG), Aspidosperma quebracho-blanco Schltdl. (Apocynaceae) (AQB), and Ilex paraguariensis St.Hil. (Aquifoliaceae) (IP). Thus, polyphenol bioavailability and oxidative effects of them were measured in different en- cephalic regions to be related to weight control.

\section{Material and Methods}

\subsection{Equipment and materials}

Fast Blue BB salt (4-benzoylamino-2,5-dimetho- xybenzenediazonium chloride hemi-(zinc chlori- de)), xylenol orange, and other chemicals were purchased from Sigma-Aldrich Co. (St. Louis, MO, USA). Solvents were obtained from Cicare- Ili SA (Argentina). Spectrophotometric readings were performed with a GloMax® Multi Microplat Multimode Reader (Promega Corp., Madison, WI, USA).

\section{a. Plant extracts}

Wild LG and AQB were collected during summer at -31.28/-64.44 GPS coordinates (mountain zone of the phytogeographic Chaquenian region, Córdoba, Argentina), with identified specimens being in the RIOC Herbarium of Argentina. Commercial IP was obtained from organic cultures. One gram of pulverized air-dried samples was extracted by adding ten $\mathrm{mL}$ of water heated at $95^{\circ} \mathrm{C}$. These infusions were allowed to cool at room tempera- ture for 1 hour in darkness under constant sha- king. Then, they were centrifuged to recover ex- tracts from each supernatant by filtration and 24-h freeze-drying. Phytochemical contents were pre- viously reported ${ }^{11}$.

\section{b. Experimental conditions}

This study was carried out according to the ethical and technical US guidelines, with the approve- ment of the Institutional Committee for the Care and Use of Laboratory Animals (National University of Cordoba, Argentina). Animals were bred under standard laboratory conditions and fed ad libitum with commercial diet $(200 \pm 13 \mathrm{~g} / \mathrm{kg} / \mathrm{d}$; Car- gill SACI, Argentina) and potable water $(150 \pm 10 \mathrm{~mL} / \mathrm{kg} / \mathrm{d}$; Aguas Cordobesas SA, Argentina). One- month-old Balb/c female mice with a $20 \%$ of body weight over the mean expected for age 13 , were separated into four experimental groups to be treated orally for 15 days: C (water without extract), AQB, LG, and IP (100 mg/kg/day of each water- dissolved extract, equivalent to the consumption of $\sim 2 \mathrm{~L}$ of infusion in humans). General status, body weight, food, and water consumption were controlled. Then, they were sacrificed. Organs were weighed and divided into different regions: brain (telencephalon and diencephalon), midbra- in, brainstem and cerebellum. These tissues were mechanically homogenized in $1.25 \mathrm{~mL}$ of $60 \%$ methanol with $62.5 \mu \mathrm{L}$ of $50 \%$ trichloroacetic acid. After 30 -min incubation at at $50^{\circ} \mathrm{C}$ in darkness to obtain polyphenols and oxidants 12 , supernatants were recovered by 5-min 10,000-rpm centrifuga- tion to perform assays with them.

\section{c. Polyphenols}

Acid-methanolic supernatants of regions were mi- xed with a 0,1\% Fast Blue BB and $20 \%$ sodium bicarbonate (volume relation $10: 1: 1$ ), for $30 \mathrm{~min}$ indarkness at $37^{\circ} \mathrm{C}$. Then, polyphenols were mea- sured at $450 \mathrm{~nm}$, to calculate gallic acid equiva- lent $\mu \mathrm{g}$ per gram of tissue using a standard curve (0.01-18.75 $\mu \mathrm{g}$ of gallic acid; Anedra, Argentina). Results were expressed as percentages respect to control (\%).

\section{Oxidants}

They were measured as previously done in central nervous system ${ }^{12}$, with absorbances being stan- dardized per tissue gram and calculated as per- centages respect to control (\%). First, superoxide anion (SO) of samples reacted $30 \mathrm{~min}$ in darkness at $37^{\circ} \mathrm{C}$ with $0.1 \%$ nitroblue tetrazolium (volume relation $9: 1$ ). Then, $2 \mathrm{M}$ potassium hydroxide and dimethylsulfoxide were added to the reaction (vo- lume relation 1:1:2). Absorbance was recorded at $600 \mathrm{~nm}$. On the other hand, hydroperoxides and lipid peroxides (HP and LP, respectively) of samples reacted $30 \mathrm{~min}$ with solution $\mathrm{A}$ (HP: $100 \mathrm{mM}$ sorbitol and $125 \mu \mathrm{M}$ xylenol orange; or LP: $4 \mathrm{mM}$ butylated 
hydroxytoluene and $125 \mu \mathrm{M}$ xylenol orange in $90 \%$ methanol) and B (25 mM ferrous ammonium sulfate in $2.5 \mathrm{M}$ sulfuric acid) (volume relation 10:100:1). Absorbance was recorded at $540 \mathrm{~nm}$.

\section{a. Statistical analysis}

Data were expressed as mean \pm standard error (SE). ANOVA models followed by the Tukey test were used to compare treatment effects (C, AQB, LG, and IP) on body weight and encephalic va- riables (tissue concentrations of polyphenols and oxidants), with $\mathrm{P}<0.05$. Spearman coefficients (SC) were utilized to evaluate correlation. The InfoStat v.2012 software was used (InfoStat Group, Argentina).

\section{b. Results}

Mice showed the following body weight gain af- ter 15 days of treatment: $\mathrm{C}: 2.80 \pm 0.20 \mathrm{~g}, \mathrm{AQB}$ :

$-0.23 \pm 0.62 \mathrm{~g}, \mathrm{IP}: 1.60 \pm 0.10 \mathrm{~g}$, and LG: $1.47 \pm 0.20 \mathrm{~g}$. This meant a weight gain reduced by the three treatments, with AQB showing a significant effect $(p<0.05)$ (Figure 1). Concerning this, AQB increased polyphenols in telencephalon, diencephalon, and significantly brainstem $(p=0.0062)$. Other experimental groups showed control levels of these compounds in the different studied encephalic regions (Figure 2).

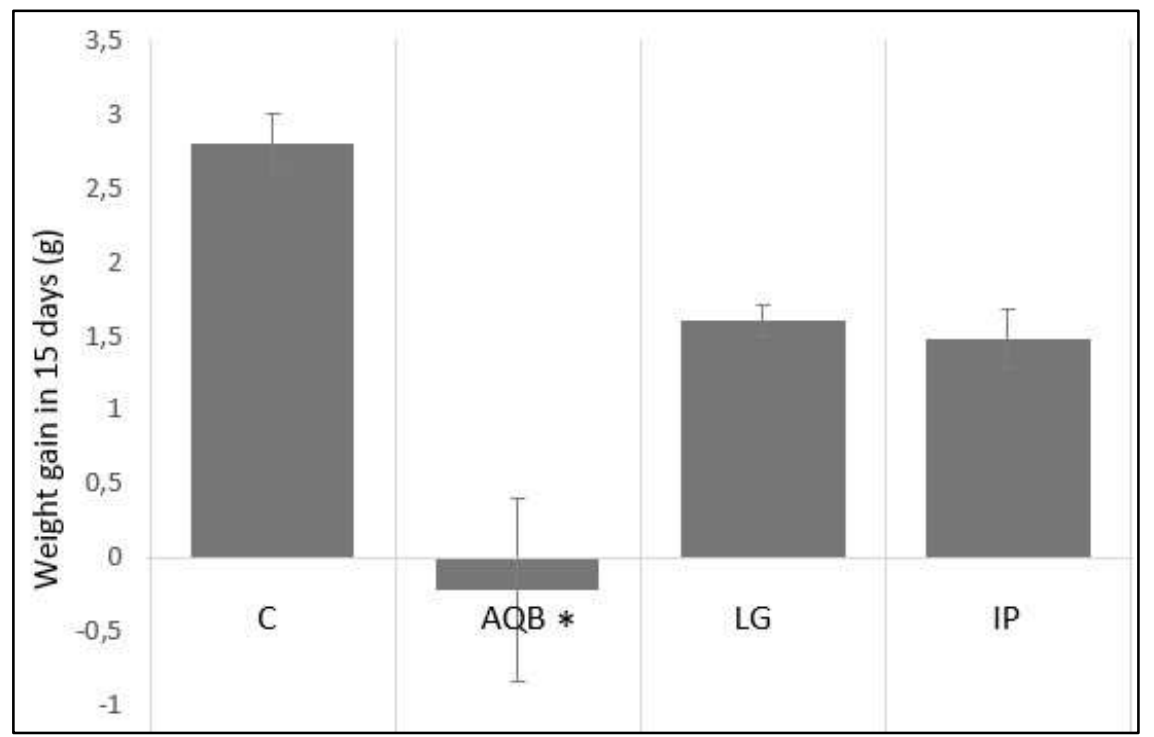

Figure 1. Weight change of Balb-c mice treated during 15 days with $100 \mathrm{mg} / \mathrm{kg} /$ day (mean $\pm S E$ of $n \geq 3$ expressed as percentages respect to $C$ ) Experimental groups compared by ANOVA $\left({ }^{*} \mathrm{p}<0.05\right)$ : C: Control (untreated); AQB: A. quebracho-blanco; IP: I. paraguariensis; LG: L. grisebachii.

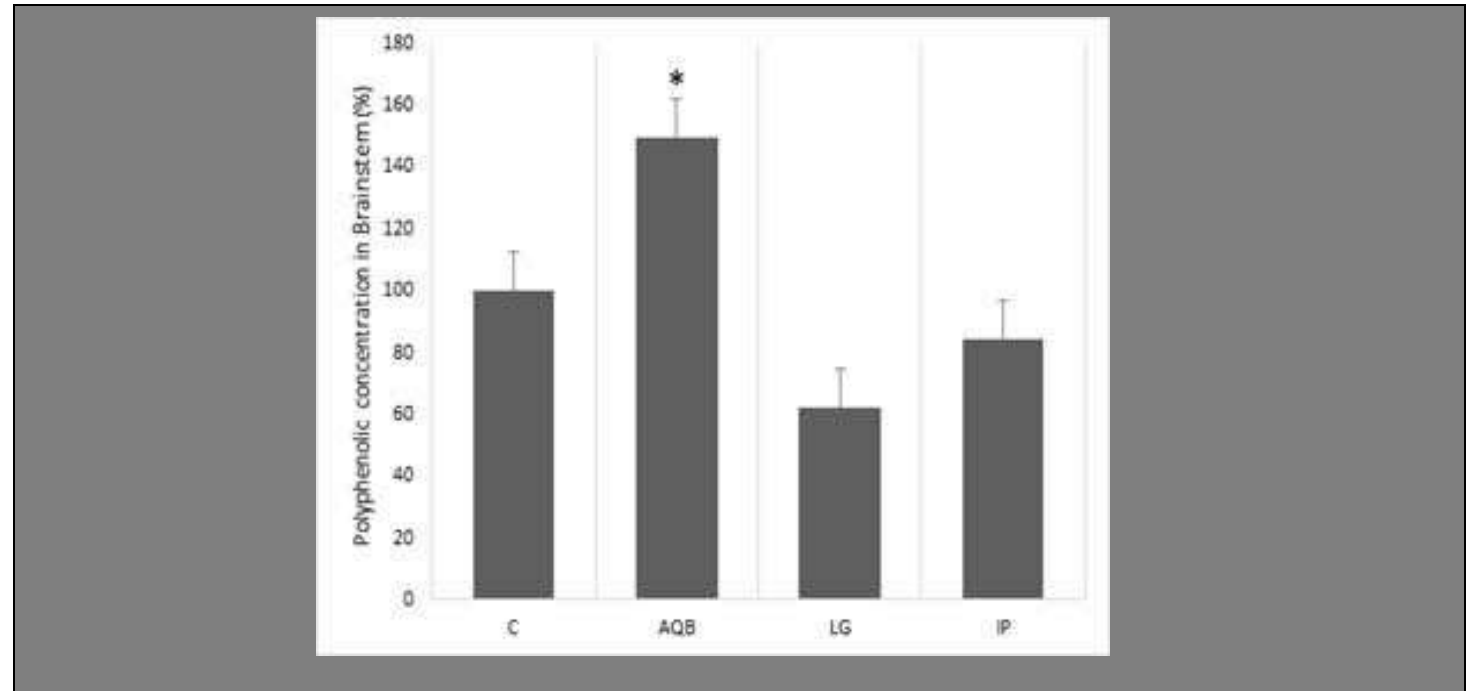

Figure 2. Polyphenols in brainstem of Balb-c mice treated during 15 days with $100 \mathrm{mg} / \mathrm{kg} /$ day (mean $\pm \mathrm{SE}$ of $\mathrm{n} \geq 3$ ex- pressed as percentages respect to $\mathrm{C}$ ). Experimental groups compared by ANOVA ( $\left.{ }^{*} \mathrm{p}<0.05\right)$ : C: Control (untreated); AQB: A. quebracho-blanco; IP: I. paraguariensis; LG: L. grisebachii. 
In telencephalon, LG, IP and AQB decreased lipid peroxides respect to $C(p=0.0029)$ (Figure 3a). In midbrain, IP increased lipid peroxides and superoxide anion respect to $C(p=0.0009$ and $p=0.0001$, respectively), whereas $L G$ reduced superoxide anion $(p=0.0001)$. AQB showed no significant effect (Figure $3 b)$. In brainstem, AQB increased superoxide anion and lipid peroxides $(p=0.0029$ and $p=0.0280$, respectively), whereas $L G$ and IP reduced hydroperoxides $(p=0.0022)$

(Figure 3c). In cerebellum, IP induced lipid peroxides ( $p=0.0008$ ), whereas LG decreased hydroperoxides $(p=0.0066)$ (Figure $3 d)$. No additional changes in oxidant levels were found in encephalon.
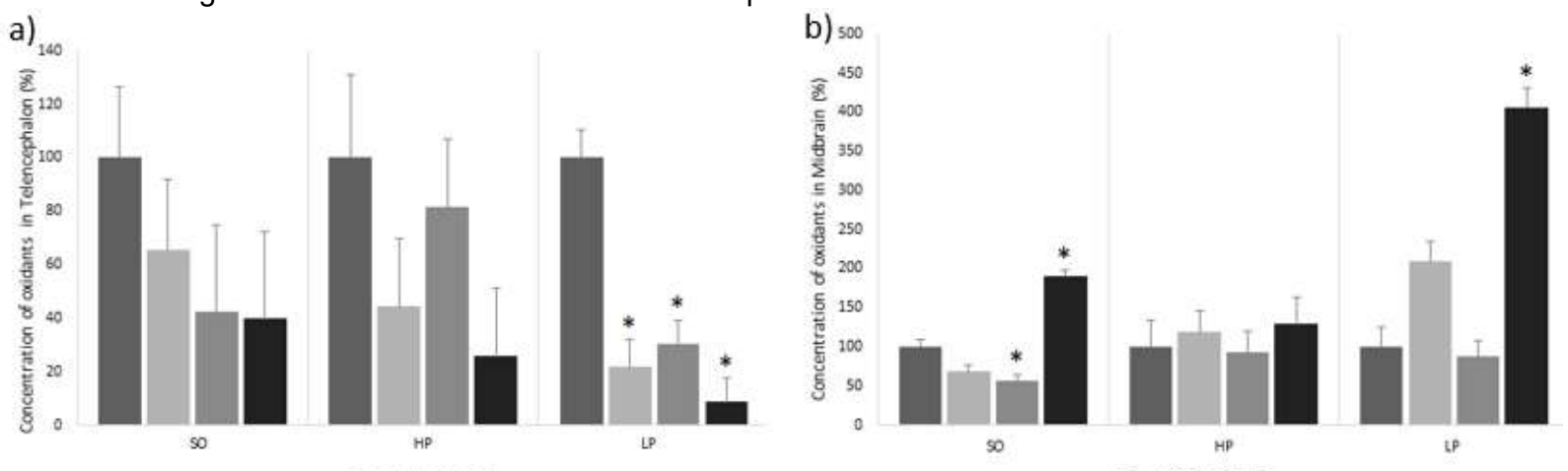

$\approx C=A O B=L E \| I P$
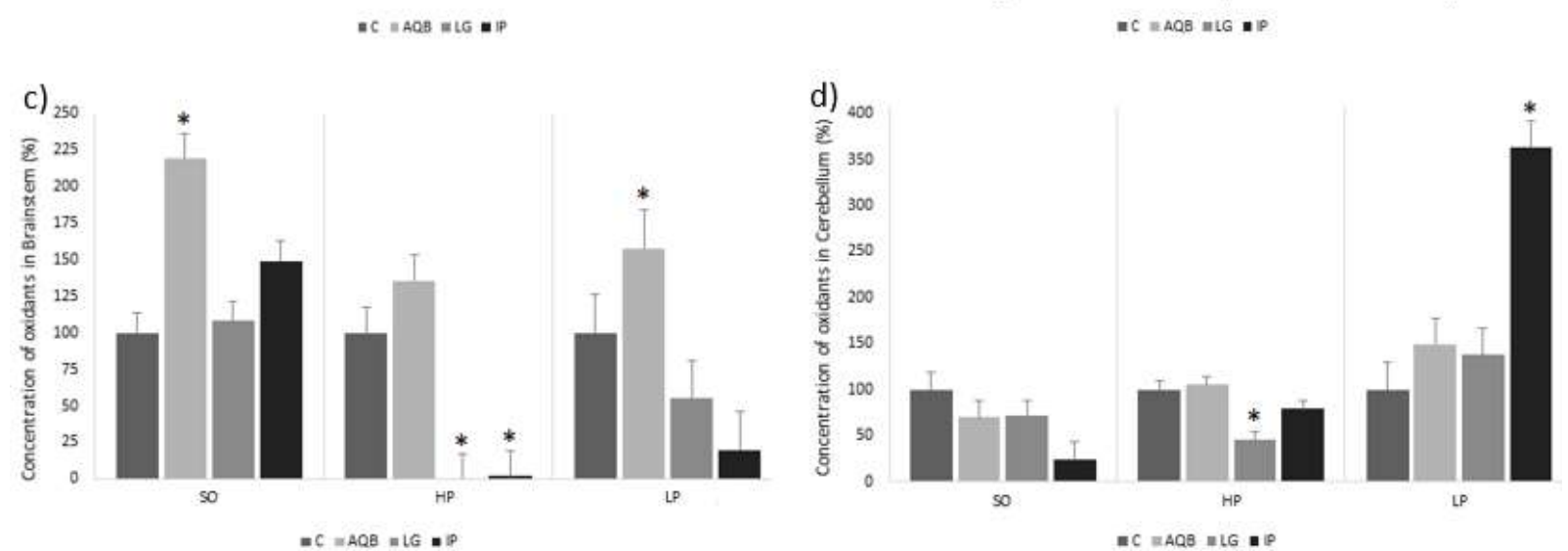

$\|C=A Q B=L M\| P$

Figure 3. Oxidants in central nervous system of Balb-c mice treated during 15 days with $100 \mathrm{mg} / \mathrm{kg} / \mathrm{day}$ (mean $\pm \mathrm{SE}$ of $\mathrm{n} \geq 3$ expressed as percentages respect to C). Experimental groups compared by ANOVA ( $\left.{ }^{*} p<0.05\right)$ : C: Control (untrea- ted); AQB: A. quebracho-blanco; IP: I. paraguariensis; LG: L. grisebachii. Abbreviations: SO: Superoxide anion; HP: hydro-peroxides; LP: lipid peroxides. 


\section{Discussion}

Although infusions from A. quebracho-blanco, I. paraguariensis and $\mathrm{L}$. grisebachii are able to modulate encephalic redox status of healthy mice ${ }^{12}$, their relevance in pathological conditions was unknown. Thus, they were assayed in mice with overweight, with own data suggesting their con- tent of bioactive compounds.

Only the AQB extract acted as a significant source of phenolic compounds able to accumulate in central nervous system, by increasing these neurotropic polyphenols in the brainstem and midbrain in a lesser extent, which was associated with reduced weight gain. Accordingly, plant polyphenols modulate physiology to counteract obesity ${ }^{14}$, involving hypothalamus, hippocampus and brainstem ${ }^{15}$, ${ }^{16}$. Furthermore, this region showed the highest polyphenolic concentration, which might include flavonoid aglycones ${ }^{17}$. Thus, they are candidates as neural and metabolic regulators ${ }^{18,19}$.

AQB treatment showed an antioxidant effect on telencephalic region associated with the reduction in weight gain. In this regard, experimental evidence establish that adequate overweight control, brain redox state and health benefits are related ${ }^{20,} 21$. However, this should be criticized, as the antioxidant activity could be temporary and/ or not having clinically relevant effects. In fact, antioxidant response to the LG extract is toxic after long-term use ${ }^{12}$. Similarly, treatment with IP showed regional differences (antioxidant in telencephalon and brainstem, but oxidant in cerebellum and midbrain). Moreover its antioxidant effect is transitory ${ }^{12}$. Therefore, this context, redox changes induced by phytochemicals are not sufficient to guarantee neuroprotection and neuroregulation. Therapeutic $A Q B$ potential is limited by the induction of oxidative stress in the brainstem, a side effect, which can be enhanced by prolonged use ${ }^{12}$. Moreover, this oxidative effect was found outside nervous system (unpublished results). Hence, it is necessary to identify and differentiate compounds responsible for its desirable and undesirable effects. This toxicity has been recognized ${ }^{22}$. However, data is contradictory ${ }^{23}$, ${ }^{24}$, which have been also seen by nutritional epidemiology ${ }^{25}$.

\section{Conclusions}

In conclusion, $A Q B$ reduced weight gain in female mice in a better way than $L G$ and $I P$, which was related to regional redox changes in encephalon. Nonetheless, oxidative stress was a side effect, which must be considered to obtain their phytochemicals to treat overweight and obesity, a major concern for human health.

\section{Funding}

ARM and MCC were supported by the Programme for Improvement of Medical Education (PROMED, Ministerio de Educación de la Nación, Argentina). This work was supported by the SECYT (Universi- dad Nacional de Córdoba, Argentina) under grant number $203 / 2014$

\section{Conflict of interest}

None of the authors have any conflicts of interest rela- ted to this manuscript.

\section{References}

1. Surh YJ. Xenohormesis mechanisms underlying chemopreventive effects of some dietary phytochemicals. Ann. N. Y. Acad. Sci. 2011;1229:1-6. DOI: 10.1111/j.1749-6632.2011.06097.x

2. Tangney C, Rasmussen HE. Polyphenols, Inflammation, and Cardiovascular Disease. Curr. Atheroscler. Rep. 2013;15:324. DOI: 10.1007/s11883-0130324-x

3. Kumar GP, Khanum F. Neuroprotecti-ve potential of phytochemicals. Pharmacogn. Rev. 2012;6(12):81-90. DOI: 10.4103/0973-7847.99898

4. Chiva-Blanch $G$, Urpi-Sarda M, Llorach $R$ et al. Differential effects of polyphenols and alcohol of red wine on the expression of adhesion molecules and inflammatory cytokines related to atherosclerosis: a randomized clinical trial. Am. J. Clin. Nutr. 2012;95:326-34. DOI: 10.3945/ajcn.111.022889

5. Vara Messler M, Cremonezzi DC, Soria EA, Eynard AR. Nutritional chemoprevention of urinary tract tumors (UTT) induced by lithogenic agents: Risk for UTT in children exposed to melamine-contamina- ted milk formulas. J. Environ. Sci. Health. C. Environ. Carcinog. Ecotoxicol. Rev. 2012; 30:174-87. DOI: 10.1080/10590501.2012.684302

6. Cave MC, Hurt RT, Frazier TH et al. Obesity, inflammation and the potential application of pharmaconutrition. Nutr. Clin. Pract. 2008;23:16-34.

7. Schwartz MV, Woods SC, Porte D, Seeley RJ, Baskin DG. Central nervous system control of food intake and body weight. Nature. 2006;443(7109):289-95 DOI: 10.1038/nature05026

8. Most J, Goossens GH, Jocken JW, Blaak EE. Short-term supplementation with a specific combina- tion of dietary polyphenols increases energy expen- diture and alters substrate metabolism in overweight subjects. Int. J. Obes. 2014;38:698-706. DOI: 10.1038/ ijo.2013.231

9. Manach C, Williamson G, Morand C, Scal- bert $A$, Rémésy C. Bioavailability and bioefficacy of polyphenols in humans. I. Review of 97 bioavailability studies. Am. J. Clin. Nutr. 2005;81:230-42.

10. Lambert JD, Sang S, Yang CS. Possible controversy over dietary polyphenols: benefits vs risks. 
Chem. Res. Toxicol. 2007;20(4):583-5. DOI: 10.1021/ tx7000515

11. Canalis AM, Cittadini MC, Albrecht C, Soria EA. Sex-related redox effects of Aspidosperma quebrachoblanco, Lantana grisebachii and Ilex paraguarien- sis on blood, thymus and spleen. Indian. J. Exp. Biol. 2014;52(9):882-9.

12. Cittadini MC, Canalis AM, Albrecht C, Soria EA. Effects of oral phytoextract intake on phenolic con- centration and redox homeostasis in murine encepha- lic regions. Nutr. Neurosci. 2015;18(7):31622. DOI: $10.1179 / 1476830514$ Y.0000000130

13. Eisen JE. Results of growth curve analyses in mice and rats. J. Anim. Sci. 1976;42:1008-23.

14. Panickar KS. Effects of dietary polyphenols on neuroregulatory factors and pathways that mediate food intake and energy regulation in obesity. Mol. Nutr. Food Res. 2013;57(1):34-47. DOI: 10.1002/ mnfr.201200431

15. Lenard NR, Berthoud HR. Central and Peripheral Regulation of Food Intake and Physical Activity: Pathways and Genes. Obesity. 2008;16(3):11-22. DOI: 10.1038/oby.2008.511

16. Sainsbury A, Zhang L. Role of the hypothalamus in the neuroendocrine regulation of body weight and composition during energy deficit. Obes. Rev. 2012;13:234-57. DOI: 10.1111/j.1467789X.2011.00948.x

17. Wiczkowski W, Skipor J, Misztal T, Szawara Nowak D, Topolska J, Piskula MK. Quercetin and isorhamnetin aglycones are the main metabolites of dietary quercetin in cerebrospinal fluid. Mol. Nutr. Food Res. 2015;59(6):1088-94. DOI: 10.1002/mnfr. 201400567

18. Bahramsoltani R, Farzaei MH, Farahani MS, Rahimi R. Phytochemical constituents as future antidepressants: a comprehensive review. Rev. Neurosci. 2015;26(6):699-719. DOI: 10.1515/revneu- ro2015-0009

19. Nabavi SF, GL Russo, Daglia M, Nabavi SM. Role of quercetin as an alternative for obesity treatment: You are what you eat!. Food Chem. 2015;179:305-10. DOI: 10.1016/j.foodchem.2015.02.006

20. Moyse E, Arseneault M, Gaudreau P, Ferland G, Ramassamy C. Gender-and region-dependent changes of redox biomarkers in the brain of successfu- lly aging LOU/C rat. Mech. Ageing. Dev. 2015;149:19- 30. DOI: 10.1016/j.mad.2015.04.002

21. Freeman LC, Ting JPY. The pathogenic role of the inflammasome in neurodegenerative diseases. J. Neurochem. 2016;136(1):29-38. DOI: 10.1111/ jnc. 13217

22. Hsieh YS, Kuo MH, Chen PN, Kuo DY. The Identification of Neuropeptide $Y$ Receptor Subtype Involved in Phenylpropanolamine-induced Increase in Oxidative Stress and Appetite Suppression. Neuromolecular Med. 2013;15(1):159-68. DOI: 10.1007/ s12017-012-8206-X

23. Juurlink BH, Azouz HJ, Aldalati AM, Altinawi
BM, Ganguly P. Hydroxybenzoic acid isomers and the cardiovascular system. Nutr. J. 2014;13:63. DOI: 10.1186/1475-2891-13-63

24. Chalansonnet M, Carabin N, Boucard S, Cosnier F, Nunge H, Gagnaire F. Study of the potential oxidative stress induced by six solvents in the rat brain. Neurotoxicology. 2013;35:71-83. DOI: 10.1016/j.neuro.2012.12.002

25. Zamora-Ros R, Rothwell JA, Scalbert $A$ et al. Dietary intakes and food sources of phenolic acids in the European Prospective Investigation into Cancer and Nutrition (EPIC) study. Br. J. Nutr. 2013;110(8):150011. DOI: 10.1007/s00394-015-0950-x 